\title{
VERTICAL JUMP PERFORMANCE AND ISOKINETIC TORQUE DISCRIMINATE ADVANCED AND NOVICE JUDO ATHLETES
}

\author{
Daniele Detanico', Juliano Dal Pupo 1 , Susane Graup², and Saray Giovana dos Santos ${ }^{1}$ \\ ${ }^{1}$ Biomechanics Laboratory, Federal University of Santa Catarina, Brazil \\ ${ }^{2}$ Physical Education Department, Federal University of Pampa, Brazil
}

Original scientific paper

UDC: 796.853.23:612.7

\begin{abstract}
:
This study aimed to analyze neuromuscular variables (vertical jump and torque in external/internal shoulder rotation) in advanced and novice judo athletes, and to identify which neuromuscular variables allow for discrimination between them. Thirty male judo athletes participated in this study: 19 novice and 11 advanced athletes. The judo athletes performed the external/internal shoulder rotation in an isokinetic dynamometer and the countermovement jump on a force platform. Student's $t$-test and the discriminant analysis were used, with the level of significance set at $5 \%$. The main results showed that the advanced judo athletes presented higher jump height $(\mathrm{p}=.03)$ and power output $(\mathrm{p}=.02)$ compared to the novice athletes. In addition, internal shoulder rotation peak torque was higher in the advanced judokas compared to the novice judokas $(p=.04)$, and the ratio between external rotation torque and internal rotation torque was higher in the novice judokas compared to the advanced judokas $(\mathrm{p}=.006)$. In this discriminant function, the variables with higher discriminatory power were (in descending order): jump height, internal shoulder peak torque, and ratio between peak torques. The results of the present study demonstrated that advanced judo athletes presented better performance in vertical jump, internal shoulder isokinetic torque, and ratio between external/ internal isokinetic torques than novice athletes. The variables used to discriminate between advanced and novice judokas may provide coaches with a guide for sport-specific training needs.
\end{abstract}

Key words: combat sports, stretch-shortening cycle, muscle strength, vertical jump

\section{Introduction}

Judo is an intermittent sport with high-intensity periods of effort. It has been documented that the typical judo combat-pause time structure contains an effort-pause ratio close to $2: 1$ or $3: 1$ (Miarka, et al., 2012, 2014). During a competitive judo match, athletes spend the majority of time in grappling disputes, aiming to dominate the opponent, disrupt the opponent's balance, and execute a throwing technique (Franchini, Brito, Fukuda, $\&$ Artioli, 2014). Movements such as pulling the opponent in an attempt to provoke his/her fall (Ruivo, Pezarat-Correia, \& Carita, 2012; Ghrairi, Hammouda, \& Malliaropoulos, 2014) and handgrip to control the distance between the judoka and the opponent are widely observed during matches (Ache Dias, et al., 2012; Bonitch-Góngora, BonitchDomínguez, Padial, \& Feriche, 2012; Franchini, Miarka, Matheus, \& Del Vecchio, 2011). In addition, during judo matches, movements of the lower limbs demand constant explosive eccentric-concentric contractions involving the stretch-shortening cycle, as in the throwing techniques (Detanico,
Dal Pupo, Franchini, \& Santos, 2012; Torres-Luke, Hernandez-Garcia, Garatachea, \& Nikolaidis, 2015). Thus, muscle strength/power in the upper and lower limbs may be considered important physical abilities related to judo performance (Franchini, Artioli, \& Brito, 2013). This was confirmed by previous studies that observed decrease of handgrip strength (Bonitch-Góngora, et al., 2012), external/ internal shoulder rotation torque, and muscle power in lower limbs (Detanico, Dal Pupo, Franchini, \& Santos, 2015) after a simulated tournament.

Neuromuscular parameters of the upper and lower limbs can be assessed by generic or sport-specific tests. It is known that higher specificity of a test leads to higher difficulty in quantifying the effort or determining physical capacities relevant to performance (Detanico \& Santos, 2012). Generic tests have been used in order to classify judo athletes and non-athletes by using, for example, a handgrip test (Ache Dias, et al., 2011), shoulder and elbow isokinetic torque test (Ruivo, et al., 2012), and vertical jump test (Monteiro, Massuça, García, Carratala, \& Proença, 2011; Zaggelidis, Lazaridis, Malkogiorgos, \& Mavrovouniotis, 2012). 
Considering the wide use of generic tests in sports training, an important question is whether these tests are able to discriminate among athletes of different training levels. The classification of athletes based on neuromuscular characteristics is relevant for identifying the level of athletes within a group and to select adequate training workload (Duncan, Hankey, Lyons, James, \& Nevill, 2013). Moreover, information regarding different neuromuscular patterns can help coaches and physical trainers to identify motor tasks relevant to specific adaptations of judo training.

The available literature points to a dearth of information regarding upper- and lower-limb strength profile in judokas at different training levels. For example, Del Vecchio, Dimare, Franchini, and Schaun (2014) verified that performance in push-up test (generic test) was different in experienced judo athletes and beginners. In addition, differences between elite judo athletes and non-elite ones were observed in the Wingate test (Franchini, Takito, Kiss, \& Sterkowicz, 2005). An important point is that in both studies only comparative analysis was used. However, a discriminant function is considered more appropriate to distinguish among various groups (Nikolaidis, \& Ingebrigtsen, 2013; Lago-Peñas, Lago-Ballesteros, Dellal, \& Gómez, 2010). Therefore, the purpose of this study was to analyze upper and lower strength parameters (vertical jump performance and external/internal shoulder rotation torque) in advanced and novice judo athletes as well as to identify whether these neuromuscular variables may discriminate between advanced and novice athletes. The main hypothesis was that the jump height and external/internal shoulder rotation torque may discriminate among judokas of different competitive levels.

\section{Methods}

\section{Participants}

Thirty male judo athletes volunteered to participate in this study: 19 were considered novice athletes (21.7 \pm 5.3 years of age; $77.7 \pm 14.0 \mathrm{~kg} ; 175.7 \pm 8.2 \mathrm{~cm}$; $13.7 \pm 3.2 \%$ of body fat; $4.3 \pm 3.1$ years of judo experience; maximum rank $2^{\text {nd }}$ kyu up to purple belt; $4 \pm 1$ hours of training per week) and 11 were considered advanced athletes $(21.3 \pm 3.2$ years of age; $76.7 \pm 13.3$ $\mathrm{kg} ; 175.0 \pm 8.6 \mathrm{~cm} ; 13.9 \pm 3.2 \%$ of body fat; $12.4 \pm 3.7$ years of judo experience; brown and black belts; $7 \pm 2$ hours of training per week). The main division criterion used in this study was the belt color (up to purple belt and brown/black belts). This criterion was previously used by Del Vecchio et al. (2014). Time of experience was also considered and it was significantly higher in advanced athletes compared to novice athletes $(\mathrm{p}<.01)$.

All athletes took part in under-100 kg weight categories. They had already participated in several national/state tournaments and trained on a regular basis (technical and tactical training) 3-4 times a week during the evaluation period. They were in the competition-preparatory phase and therefore not in a period of rapid weight loss. All participants were informed about the study procedures and signed the informed consent form, in accordance with the Declaration of Helsinki. This study was approved by the Research Ethics Committee of the local university (protocol number: 119.014).

\section{Measures and procedures}

The following assessments were performed: anthropometric evaluation, external/internal shoulder rotation isokinetic torque and countermovement jump (CMJ) at a room temperature of $24^{\circ} \mathrm{C}$. Participants were instructed to maintain normal diets and to avoid drinking alcohol or taking any medications 24 hours prior to the assessments. All athletes participating in the study declared that they did not take any prohibited drugs.

Initially, body mass, body height and skinfold thickness (triceps, subscapular, suprailiac and medial calf) values were collected. All measurements were performed by an experienced evaluator (level 1 of the International Society for Advancement in Kinanthropometry - ISAK). The Petroski equation (Petroski \& Pires-Neto, 1996) was used to estimate body density, and Siri equation was used to calculate percent of body fat. After this, the participants were familiarized with the testing procedures and performed 3-4 submaximal repetitions of external and internal shoulder rotations on an isokinetic dynamometer (Biodex Multi-Joint System-Pro 4, Biodex Inc., New York, USA). Five minutes later participants performed one set of four maximal external and internal shoulder rotations, in concentric/concentric mode at $180 \%$ s, using their dominant arm (Ruivo, et al., 2012). During the test, participants were seated on the dynamometer in an adjustable chair with test positions recorded and repeated for each participant in subsequent trials. The athlete's body was fixed by belts that crossed the trunk and pelvic regions. The athlete's arm was statically weighted to provide gravity compensation. External and internal shoulder rotation torque was measured with the arm abducted at $45^{\circ}$. Based on a reference position $\left(0^{\circ}\right)$ with the forearm in the vertical position, the range of motion was set at $70^{\circ}$. Rotation movements were performed with $0^{\circ}$ fixed as the beginning of an internal rotation and $70^{\circ}$ as the end of the internal rotation/beginning of an external rotation. Visual feedback and strong verbal encouragement were provided to the participants.

The torque data were initially filtered using a $4^{\text {th }}$-order Butterworth low-pass filter at $20 \mathrm{~Hz}$, and for the angular data, this same filter was applied with a cut-off frequency of $10 \mathrm{~Hz}$. From the filtered data, the following variables were calcu- 
lated: external rotation shoulder peak torque $\left(\mathrm{PT}_{\mathrm{EX}}\right)$, internal shoulder rotation peak torque $\left(\mathrm{PT}_{\mathrm{IN}}\right)$, and ratio between the external and internal peak torque (ER:IR). The data were processed in an algorithm implemented in MATLAB software (MathWorks, Massachusetts, USA).

The CMJ assessment was preceded by a familiarization period with testing procedures and by a warm-up that consisted of 30 seconds of hopping on a trampoline, three sets of 10 hops on the ground, and eight submaximal vertical jumps simulating the real test task. After that, the judokas performed three maximal CMJs on a piezoelectric force platform (Quattro Jump, model 9290AD, Winterthur, Switzerland) set at a frequency of $500 \mathrm{~Hz}$. Participants were instructed to jump as high as possible while keeping their trunk as vertical as possible and their hands placed on the hips (Dal Pupo, Detanico, \& Santos, 2012). Ground reaction force data was filtered using a $4^{\text {th }}$-order Butterworth low-pass filter at $20 \mathrm{~Hz}$. Force data was double integrated to obtain jump height and mean power output during the positive phase of the jump. The best jump (greater height) was considered for analysis. bles that discriminate between novice and advanced athletes. It was considered as relevant for the interpretation of the linear vectors that the structural coefficient be above 0.30 (Tabachnick \& Fidell, 2007). The significance level was set at $\mathrm{p}<.05$ for all tests. These analyses were performed using the Statistical Package for Social Sciences (SPSS Inc. v.17.0, Chicago, USA) software.

\section{Results}

Table 1 shows the variables of CMJ (jump height and power output), peak torque of internal $\left(\mathrm{PT}_{\mathrm{IN}}\right)$ and external $\left(\mathrm{PT}_{\mathrm{EX}}\right)$ shoulder rotation and the ratio between the external and internal peak torque (ER:IR) in the novice and advanced judo athletes. The advanced judo athletes presented greater jump height, power output and $\mathrm{PT}_{\mathrm{IN}}$ than the novice athletes. The ER:IR ratio was higher in the novice judokas when compared to the advanced judokas. $\mathrm{PT}_{\mathrm{EX}}$ did not differ between the groups.

The structural coefficients from the discriminant analysis of the neuromuscular variables measured in the advanced and novice athletes are described in Table 2. In this discriminant function,

Table 1. Mean and standard deviations of CMJ and shoulder rotation isokinetic torque in novice and advanced judo athletes

\begin{tabular}{lcccc}
\hline & $\begin{array}{c}\text { Novice athletes } \\
(\mathrm{n}=19)\end{array}$ & $\begin{array}{c}\text { Advanced athletes } \\
(\mathrm{n}=11)\end{array}$ & $\mathrm{p}$-value & ES \\
\hline Jump height $(\mathrm{cm})$ & $43.7 \pm 4.6$ & $49.5 \pm 4.9$ & .003 & $1.23 \S$ \\
Power output $(\mathrm{W} / \mathrm{kg})$ & $26.2 \pm 3.6$ & $30.5 \pm 3.8$ & .005 & $1.16^{\S}$ \\
$\mathrm{PT}_{\text {IN }}(\mathrm{N} \cdot \mathrm{m})$ & $59.0 \pm 11.7$ & $70.1 \pm 17.2$ & .04 & $0.78^{\#}$ \\
$\mathrm{PT}_{\text {EX }}(\mathrm{N} \cdot \mathrm{m})$ & $48.5 \pm 10.1$ & $48.9 \pm 7.4$ & .90 & $0.05^{\dagger}$ \\
ER:IR & $0.83 \pm 0.07$ & $0.72 \pm 0.12$ & .006 & $1.10^{\S}$ \\
\hline
\end{tabular}

Note. $\mathrm{PT}_{\text {IN }}$ : internal shoulder rotation peak torque; $\mathrm{PT}_{\mathrm{Ex}}$ : external shoulder rotation peak torque; $\mathrm{ER}: \mathrm{IR}$ external to internal peak torque ratio; ES: effect size; § moderate effect; \# small effect; † trivial effect.

\section{Statistical analysis}

Data were reported as means and standard deviations. A Shapiro-Wilk test was performed to verify data normality. All variables were considered with normal distribution of data. Thus, Student's $t$-test for independent samples was used to compare the neuromuscular variables between novice and advanced judo athletes. In addition, the effect size was calculated using G*Power 3.1.7 software (University of Kiel, Kiel, Germany), and the Rhea (2004) criterion was used for athletes recreationally trained (1-5 years of consistent training). Further, discriminant analysis was conducted to identify the statistical team variables that discriminate between the levels of training (novice and advanced athletes). The colinearity of data was tested in order to identify possible correlations between independent variables. The variable power output was excluded from the discriminant analysis model since it showed high correlation with jump height. A structural coefficient was used in order to identify the varia-
Table 2. Structural coefficients from the discriminant analysis of the neuromuscular variables between advanced / novice athletes and canonical discriminant function

\begin{tabular}{lc}
\hline Neuromuscular variables & Function 1 \\
\hline Jump height & $.57^{*}$ \\
ER:IR & $-.52^{*}$ \\
$\mathrm{PT}_{\text {IN }}$ & $.37^{*}$ \\
$\mathrm{PT}_{\mathrm{EX}}$ & .02 \\
Canonical discriminant function & Function 1 \\
\hline Canonical correlation & .73 \\
Eigenvalue & 1.16 \\
Wilk's Lambda & .46 \\
Chi-square & 19.98 \\
p-value & .001 \\
\hline
\end{tabular}

Note. *Structural coefficient discriminant value $>.30$. $\mathrm{PT}_{\text {IN }}$ : internal shoulder rotation peak torque; $\mathrm{PT}_{\mathrm{EX}}$ : external shoulder rotation peak torque; ER:IR external to internal peak torque ratio. 
Table 3. Absolute and relative frequency of the reclassification of groups according to the discriminant function

\begin{tabular}{lcc}
\hline Original group & \multicolumn{2}{c}{ Predicted group membership } \\
\hline & Advanced athletes & Novice athletes \\
\cline { 2 - 3 } Advanced athletes (11) & $72.7 \%(8)$ & $27.3 \%(3)$ \\
Novice athletes (19) & $10.5 \%(2)$ & $89.5 \%(17)$ \\
\hline
\end{tabular}

the variables with significant discriminatory power ( $\mathrm{SC}>$.30) were: jump height, $\mathrm{PT}_{\mathrm{IN}}$ and ER:IR ratio. The variable $\mathrm{PT}_{\mathrm{EX}}$ did not discriminate between the advanced and novice judo athletes.

Table 3 shows allocation into groups by the results, and reclassification according to the values of discriminant function. According to the discriminant function, $83.3 \%$ of athletes were correctly reclassified into the groups, indicating a high percentage of agreement between the original and predicted groups.

\section{Discussion and conclusions}

The ability to manifest strength and power has been considered a potential predictor of judo performance (Franchini, et al., 2011; Ghrairi, et al., 2014; Ruivo, et al., 2012). According to Franchini et al. (2013), high muscular strength and power is required mainly during grappling disputes and for the execution of throwing techniques involving both the lower- and upper-body muscle groups. Thus, the first aim of this study was to compare strength parameters of the lower (vertical jump performance) and upper body (external/internal shoulder rotation torque) between advanced and novice judo athletes. The results showed that the advanced athletes presented better performance in CMJ than the novice athletes. Similar results were found in the study by Monteiro et al. (2011) that showed higher eccentric force and power (CMJ) in the senior judo athletes when compared to the junior athletes and non-judo athletes. Although considered a generic test, the CMJ presents certain characteristics that may be found in sports movements. During a countermovement jump, an athlete executes concentric muscle contraction (positive phase) immediately preceded by an eccentric phase (negative phase), which allows stored elastic energy to be reused in the concentric contraction, resulting in increased movement efficiency (Komi, 2000). This mechanism, called the stretch-shortening cycle, is observed in some judo movements - for example, in throwing techniques (Detanico, et al., 2012; Torres-Luke, et al., 2015). In addition, high force levels during the negative phase of the CMJ allow the achievement of higher acceleration rates in the positive phase of movement; consequently, better vertical jump performance may be achieved (Linthorne, 2001; Dal Pupo, et al., 2012). Thus, experienced judo athletes seem to use the stretch- shortening cycle more effectively, optimizing the power output production during the jump (Zaggelidis, et al., 2012).

The advanced athletes also presented better performance (i.e. peak torque) in internal shoulder rotation than the novice athletes. Shoulder rotations are widely used during matches, especially when a judo athlete pulls the opponent, trying to provoke a fall (external rotation) (Ruivo, et al., 2012), and during grip combat in order to control the distance between the judoka and the opponent (internal rotation) (Detanico, et al., 2015). Thus, we expected higher neuromuscular adaptation of both internal and external shoulder rotation muscles in advanced athletes; however, this was not found for the external shoulder rotation torque.

The ER:IR ratio was lower in advanced athletes compared to novices, presenting the average values close to .72 and .83 , respectively. According to Ivey, Calhoun, Rusche, and Bierschenk (1985), the internal shoulder rotation strength must be greater than the external rotation by the ratio of $3: 2$ - i.e. the ER:IR ratio should be close to .66. In the present study, the advanced judokas showed values closer to this range. Muscular imbalance has been considered an important risk factor for musculoskeletal injuries because it decreases the glenohumeral joint stability (Ellenbecker \& Davies, 2000; Ellenbecker $\&$ Roetert, 2003), thus impairing the efficiency of judo actions involving rotational shoulder movements. Based on this we can say that the experienced judo athletes in our study had a lower risk factor for musculoskeletal injuries compared to the novice judokas. Additionally, Ruivo et al. (2012) also found lower values of ER:IR ratio in judokas with 14 years of judo practice compared to nonjudokas. However, the authors did not make a comparison with novice athletes. This improved balance of shoulder muscles may be attributed to a judo-specific training, such as repetitive technical practice with a single partner executing the technique without throwing (uchi-komi), repetitive throwing practice with a single partner executing the technique (nage-komi) and combat or fight practice (randori) (Franchini, et al., 2014).

The second aim of this study was to identify whether the neuromuscular variables may discriminate between the advanced and novice athletes. Thus, a novel and important finding of this study indicates that jump height was the best discriminant factor of judokas of different training levels (advanced and novice). In addition, the variables of internal shoulder rotation peak torque and the ER:IR ratio may also discriminate between the groups; these results confirm the main hypothesis of the study. The discriminant function was $83.3 \%$ correctly reclassified, indicating a high percentage of agreement between the original and predicted 
groups, according to the criterion of Tabachnick and Fidell (2007). The discriminant function seems to be stronger in classifying novice athletes than the advanced ones, i.e. $89.5 \%$ of the athletes originally classified as novice were reclassified (prediction function) as novices, while $72.7 \%$ of the athletes originally classified as advanced were reclassified as advanced (Table 3).

This finding provides important information mainly for identifying novice athletes by considering their physical condition, and using this as a reference for coaches to guide training sessions. Vertical jump, which provides the best discriminant variables, has been the most frequently and routinely used movement for evaluating the lowerlimb power output of athletes (Diaz-Lara, García, Monteiro, \& Abian-Vicen, 2014; Duncan, et al., 2013; Monteiro, et al., 2011; Zaggelidis, et al., 2012). Besides discriminating between judokas of different levels, vertical jump test has also been considered a good discriminant tool of the physical condition in other sports (Nikolaidis \& Inge- brigtsen, 2013). It is noteworthy that the vertical jump variables can be easily assessed and subsequently used by coaches and physical trainers to classify the level of athletes within a group and to design training programs according to the specific necessities of athletes (Duncan, et al., 2013).

We concluded that the advanced judo athletes presented better performance in vertical jump, internal shoulder isokinetic torque, and ratio between external/internal isokinetic torque tests than the novice athletes. Additionally, the variables that better discriminate between advanced and novice athletes were jump height, internal shoulder peak torque and ratio between external/ internal shoulder isokinetic torques. These variables can be used by coaches and physical trainers as a reference to classify advanced and novice judo athletes, promoting improvements in their physical training. Futures studies should be conducted with a larger sample size in order to propose normative data for the neuromuscular variables according to training levels.

\section{References}

Ache Dias, J., Wentz, M., Külkamp, W., Mattos, D., Goethel, M., \& Borges Júnior, N. (2012). Is the handgrip strength performance better in judokas than in non-judokas? Science \& Sports, 27, 9-14.

Bonitch-Góngora, J., Bonitch-Domínguez, J.G., Padial, P., \& Feriche, B. (2012). The effect of lactate concentration on the handgrip strength during judo bouts. Journal of Strength and Conditioning Research, 26, 1863-1871.

Dal Pupo, J., Detanico, D., \& Santos, S.G. (2012). Kinetic parameters as determinants of vertical jump performance. Brazilian Journal of Kinanthropometric and Human Performance, 14, 41-51.

Del Vecchio, F.B, Dimare, M., Franchini, E., \& Schaun, G.Z. (2014). Physical fitness and maximum number of all-out hikidashi uchi-komi in judo practitioners. Medicina Dello Sport, 67, 383-396.

Detanico, D., Dal Pupo, J., Franchini, E., \& Santos, S. (2012). Relationship of aerobic and neuromuscular indexes with specific actions in judo. Science \& Sports, 27, 16-22.

Detanico, D., Dal Pupo, J., Franchini, E., \& Santos, S. (2015). Effects of successive judo matches on fatigue and muscle damage markers. Journal of Strength and Conditioning Research, 29, 1010-1016.

Detanico, D., \& Santos, S.G. (2012). Specific evaluation in judo: A review of methods. Brazilian Journal of Kinanthropometric and Human Performance, 14, 738-748.

Diaz-Lara, F.J, García, J.M.G, Monteiro, L.F., \& Abian-Vicen, J. (2014). Body composition, isometric hand grip and explosive strength leg - Similarities and differences between novices and experts in an international competition of Brazilian jiu-jitsu. Archives of Budo, 10, 211-217.

Duncan, M.J., Hankey, J., Lyons, M., James, R.S., \& Nevill, A.M. (2013). Peak power prediction in junior basketballers: Comparing linear and allometric models. Journal of Strength and Conditioning Research, 27, 597-603.

Ellenbecker, T.S., \& Davies, G.J. (2000). The application of isokinetics in testing and rehabilitation of the shoulder complex. Journal of Athletic Training, 35, 338-350.

Ellenbecker, T., \& Roetert, E.P. (2003). Age specific isokinetic glenohumeral internal and external rotation strength in elite junior tennis players. Journal of Science and Medicine in Sport, 6, 63-70.

Franchini, E., Artioli, G.G., \& Brito, C.J. (2013). Judo combat: Time-motion analysis and physiology. International Journal of Performance and Analysis in Sport, 13, 626-643.

Franchini, E., Brito, C.J., Fukuda, D.H., \& Artioli, G.G. (2014). The physiology of judo-specific training modalities. Journal of Strength and Conditioning Research, 28, 1474-1481.

Franchini, E., Miarka, B., Matheus, L., \& Del Vecchio, F. (2011). Endurance in judogi grip strength tests: Comparison between elite and non-elite judo players. Archives of Budo, 7, 1-4.

Franchini, E., Takito, M.Y, Kiss, M.A.P.D.M., \& Sterkowicz, S. (2005). Physical fitness and anthropometrical differences between elite and non-elite judo players. Biology of Sport, 22, 315-328. 
Ghrairi, M., Hammouda, O., \& Malliaropoulos, N. (2014). Muscular strength profile in Tunisian male national judo team. Muscles Ligaments Tendons Journal, 4, 149-153.

Ivey, F.M. Jr., Calhoun, J.H., Rusche, K., \& Bierschenk. J. (1985). Isokinetic testing of shoulder strength: Normal values. Archives of Physical Medicine and Rehabilitation, 66, 384-386.

Komi, P.V. (2000). Stretch-shortening cycle: A powerful model to study normal and fatigued muscle. Journal of Biomechanics, 33, 1197-1206.

Lago-Peñas, C., Lago-Ballesteros, J., Dellal, A., \& Gómez. M. (2010). Game-related statistics that discriminated winning, drawing and losing teams from the Spanish Soccer League. Journal of Sports Science and Medicine, 9, 288-293.

Linthorne, N.P. (2001). Analysis of standing vertical jumps using a force platform. American Journal of Physiology, 69, 1198-1204.

Miarka, B., Cury, R., Julianetti, R., Battazza, R., Julio, U.F., Calmet, M., \& Franchini, E. (2014). A comparison of time-motion and technical-tactical variables between age groups of female judo matches. Journal of Sports Science, 2, 1-10.

Miarka, B., Panissa, V.L., Julio, U.F., Del Vecchio, F.B., Calmet, M., \& Franchini, E. (2012). A comparison of timemotion performance between age groups in judo matches. Journal of Sports Science, 30, 899-905.

Monteiro, L.F., Massuça, L.M., García, J.G., Carratala, V., \& Proença, J. (2011). Plyometric muscular action tests in judo- and non-judo athletes. Isokinetics and Exercise Sciences, 19, 287-293.

Nikolaidis, P.T., \& Ingebrigtsen, J. (2013). Physical and physiological characteristics of elite male handball players from teams with a different ranking. Journal of Human Kinetics, 38, 115-124.

Petroski, E.L., \& Pires-Neto, C.S. (1996). Validation of anthropometric equations for estimating body density in men. [In Portuguese.] Brazilian Journal of Physical Activity and Health, 1, 5-14.

Rhea, M.R. (2004). Determining the magnitude of treatment effects in strength training research through the use of the effect size. Journal of Strength and Conditioning Research, 18, 918-920.

Ruivo, R., Pezarat-Correia, P., \& Carita, A.I. (2012). Elbow and shoulder muscles strength profile in judo athletes. Isokinetics and Exercise Sciences, 20, 41-45.

Tabachnick, B.G., \& Fidell, L.S. (2007). Using multivariate statistics. Boston: Allyn and Bacon.

Torres-Luque, G., Hernandez-Garcia, R., Garatachea, N., \& Nikolaidis, P.T. (2015). Anthropometric characteristics and neuromuscular function in young judo athletes by sex, age and weight category. Sport Science and Health, 11, 117-124.

Zaggelidis, G., Lazaridis, S.N., Malkogiorgos, A., \& Mavrovouniotis, F. (2012). Differences in vertical jumping performance between untrained males and advanced Greek judokas. Archives of Budo, 8, 87-90.

Submitted: June 12, 2015

Accepted: December 3, 2015

Correspondence to:

Daniele Detanico, Ph.D.

Federal University of Santa Catarina,

Center of Sports, Biomechanics Laboratory

ZIP-CODE: 88040-900

Florianópolis, Santa Catarina, Brazil

Phone/fax: +55 48 3721-8530

E-mail: d.detanico@ufsc.br 